\title{
Review: Insects in and out
}

\author{
Chapman, R.F. 1998: The Insects (Structure and Function). Cambridge University Press, Cambridge. \\ Pp. 770.
}

There is no doubt that R. F. Chapman knows his insects in and out. His book "THE INSECTS - Structure and Function" first appeared in 1969, then published by Edward Arnold; the fourth edition of the book was recently released by Cambridge University Press. In 1970, when I became aware of that new, massive book of Chapman's, I was a young entomology Ph.D.-student in Australia, and I immediately found the book inimitable. It did not bother me that Chapman's hefty volume omitted information on insect classification; on the contrary I enjoyed that because it covered ground that other insect books had neglected. At that time there were few modern entomology textbooks around which focused principally on functional anatomy and Chapman's approach of not dwelling on classification, but concentrating on anatomy and physiology was of immense appeal to me, since I knew my systematics well.

The latest edition follows that original concept and, therefore, in order to get the most out of the book of 770 pages, a solid grounding in insect systematics and phylogeny is an absolute prerequisite. Given the cost of the book (54.- US\$) I wonder, however, whether the entomology students of today find the absence of taxonomy in Chapman's book a trump or a drawback. The book does, however, have a taxonomic (as well as subject) index, allowing readers to look up on which page or pages their 'favourite' hexapod (or organ) is mentioned, provided readers follow these instructions (and I quote from the unnumbered page inserted into Chapman's tome between pages 740 and 741): "All page numbers higher than 415 are incorrect in these indexes. To obtain the correct page number subtract 2 from each page number higher than $415^{\prime \prime}$. I find such an error in indexing extraordinary and inexcusable in this time and age of computerisation and can only imagine what the author must have felt when he discovered this blunder by a reputable publisher. I also sympathise with Chapman when he writes in his Preface to the book that it was "not without misgivings" that American spellings were used throughout the book and he confesses "that 'esophagus' does stick in the gullet!"

Times, of course, have changed since 1969 and many excellent new entomology books have appeared, most of them not following Chapman's example of divorcing insect function from insect nomenclature and most of them being multi-author rather than single author works. For a single person to, nowadays, cover the entire field of entomolgy is outright impossible and one wonders whether even insect physiology or functional anatomy can be treated adequately by a one person alone. For undergraduate teaching I prefer textbooks like Evans et al. (1984) or Borror et al. (1989) that do not ignore insect evolution and classification, but which at the same time provide sufficient information on insect physiology, anatomy, behaviour, and ecology to allow students to understand how insects 'function' on their own and as part of an ecosystem.

Given the explosion of discoveries in the entomological field over the last two decades, Chapman has done remarkably well to incorporate recent results in his THE INSECTS, but he admits in his preface that regrettably it was impossible for him to do justice to the enormous advances in the field of insect molecular biology. As can be expected from a book of that size when going through it chapter by chapter, section by section, some areas were obviously served better than others. Which areas can be a matter of contention amongst different expert reviewers. I find the pages on digestion and nutrition very good, but just like the equally excellent sections on gas exchange, temperature relationships and cryptobiosis a bit too long. I would have preferred to see a more up-to-date and comprehensive treatment of insect ontogeny and embryology; sections on bioluminescence, muscle, and vision, for instance, could also have benefitted from a more extensive incorporation of recent discoveries. The inclusion of more clear and easily understandable tables, for example on the longevity of selected insect species, on average duration of larval life, on growth characteristics, on numbers of facets, flicker fusion frequencies or sound parameters would have been nice.

The book follows the original layout and contains few photographs (which is not at all a disadvantage, because of the large number of schematic line drawings, many of them 'old friends' from the first edition). It is divided into 5 parts: I. Head, Ingestion, Utilization and Distribution of Food; II. Thorax and Locomotion; III. Abdomen, Reproduction and Development; IV. Integument, Gas Exchange and Homeostasis; V. Communication. The book starts with a very brief characterization of the insect, introducing terms like "sclerite", "pleura", "tergum", etc. without, unfortunately, providing a schematic drawing of "the model" insect to show the places of the pleura, sclerites, etc. Obviously Chapman has had his own reasons for arranging the chapters and sections in the way he did, but I found it a bit strange that the integument is not dealt with until page 415 and that information on moulting is split into one part on page 427 and another, in the section on endocrine systems, on page 571. Chapman's contents arrangement and topic selections do lead to a certain amount of repetitiveness and ambiguity: where, for instance, should the book deal with silk production, caterpillar locomotion, or prey capture? As is, Chapman decided to cover 
silk production in Part I under "head glands" while caterpilIar locomotion forms a brief component of the section headed "Thorax"; prey capture even if it involves vision, the legs and locomotion becomes paragraph 2.2.3 of the second chapter (=Mouthparts and Feeding) of Part I. Alimentary canal, digestion, and absorption are also located in Part I, while the excretory systems are placed into Part IV (not as one might have expected together in Part III, the one dedicated to the abdomen).

Parts, chapters, sections, and paragraphs are numbered hierarchically, e.g. Part V = Communication; Chapter $22=$ Vison; 22.2 = Functioning of the eye; 22.2.1 = Image formation, etc. So far so good, but instead of numbering corresponding figures likewise, they do not follow the hierarchical system. Consequently Fig. 22.5, for example, has nothing to do with section 22.5 (but happens to belong to section 22.1.3.2) and Fig. 22.12 does not accompany sections 22.1 or 22.1.2, but illustrates section 22.2.4.1. Somewhat confused? Well, I was when trying to match up illustrations referred to in the text with their positions in the book.

Yet, there can be no doubt that whatever shortcomings the book may reveal to the various readers, the text has its usefulness, even today in the age of internet searches and online information. Here, in one book, the entomological student or researcher can find a wealth of information on insect structures and functions. I found few outrightly wrong statements like, for instance, on p. 668 that UV-wing patterns were caused by structural colours alone (pierid butterflies possess UV-pigments: Yagi 1954) or erroneous citations (for example on p. 606, where Meyer-Rochow 1975 was cited, but Meyer-Rochow 1974 would have been correct). It is almost impossible not to expect the author would have omitted, either accidentally or for deliberate reasons, some information deemed important by one or the other reader. I was surprised not to find mycetophilids and their 'fishing lines' mentioned in the paragraphs dealing with insect silk, or the 'jet-propulsion' mechanism of whirligig beetles in the section on locomotion, or Antti Jansson's comprehensive studies on waterbug stridulation in the insect communication chapter, etc., etc. The selection of the right references is, of course, always a sore point and to cite Hinton's 1963 paper as "the most recent review on the function of the insect pupal stage" simply cannot be right. On the other hand the fact that Chapman tries to distinguish between relevant research papers and recent/comprehensive reviews (those that he finds particularly useful and he then mentions at the end of each section), is an excellent idea and helpful to students.

In summary, Chapman's book would be a useful addition to the collection of entomological literature of those students and researchers who are familiar with the classification, evolution, and zoogeography of insects and who have a need to find out more about functional anatomy on a comparative basis. The book is not a procedural manual or methods text; it was, of course, never meant to be that or even a dictionary. However, the experimental entomologist can undoubtedly gain some insights and learn where gaps in our knowledge of insect structure and function remain. Not merely a bank of information, the book can, thus, stimulate and open our eyes towards the many unsolved questions that remain in our quest to understand the insects, in and out.

Borror, D.J., Triplehorn, C.A. \& Johnson, N.F. 1989: An introduction to the study of insects. - Saunders, Philadelphia, 875 pp.

Evans, H.E., Brewer, J.W., Capinera, J.L., Cates, R.G., Eickwort, G.C. \& Happ, G.M. 1984: Insect biology. — Addison-Wesley, Reading, 436 pp.

Hinton, H.E. 1963: The origin and function of the pupal stage. -Proc. Roy. Entomol. Soc. London A 38: 77-85.

Meyer-Rochow, V.B. 1974: Structure and function of the larval eye of the sawfly Perga (Hymenoptera). - J. Insect Physiol. 20: 1565-1591.

Yagi, N. 1954: Note of electron microscope research on pterin pigment in the scales of pierid butterflies. - Annot. Zool. Japon. 27:113-114 